\title{
Effectiveness of Electricity Derivatives Market Based on Hurst Exponent
}

\author{
Yunzhi Fei ${ }^{1, *}$, Xufang Shao ${ }^{2}$, Gang Wang ${ }^{2}$, Li Zhou ${ }^{1}$, Xue Xia ${ }^{1}$, and Yongxiu $\mathrm{He}^{1}$ \\ ${ }^{1}$ School of Economics and Management, North China Electric Power University, Beijing, 102206, China \\ ${ }^{2}$ State Grid Energy Research Institute CO., LTD, Beijing 100052, China
}

\begin{abstract}
The Rescaled Range Analysis method (R/S Analysis method) is applied to analyze the PJM electricity derivatives market through calculating V statistics and Hurst Exponent of three types of products. The study finds that there is no obvious average cycle in the PJM electricity derivatives market. The price fluctuation of various products is not a non-random walk process but has a long-term memory. It shows that the PJM electricity derivatives market is not completely effective. The study also finds that PJM electricity option market is more effective than PJM electricity futures market.
\end{abstract}

\section{Introduction}

With the development of the electricity spot market in China, constructing a corresponding electricity derivatives market has gradually been put on the agenda in order to adapt to the non-storage characteristic of electricity and prevent the sharp fluctuation of electricity price. As a part of market mechanism design, it has been an urgent problem to how to test the effectiveness of electricity derivatives market.

In terms of the theory of financial market effectiveness, Fama ${ }^{[1]}$ and Peter ${ }^{[2]}$ proposed the theories of Efficient Market Hypothesis (EMH) and Fractal Market Hypothesis (FMH) respectively. The former considers that the market whose price fully reflects all available information is an effective market, and the market efficiency can be divided into weak-effective, medium-strong-effective and strong-effective according to the types of available information, The latter considers that a stable market has a typed structure, and investors' behavior is influenced by the degree of information acceptance and the investment time scale. The traditional weak validity test has been proved to be undesirable restricted by several factors, such as Independent Identical Distribution Hypothesis ${ }^{[3,4]}$. Scholars in various countries mainly adopt the idea of fractal analysis to study the effectiveness of the market ${ }^{[5-7]}$.

In the research of futures market validity verification, Some authors use sequential test and run-length test to study metal futures and soybean futures respectively ${ }^{[3-4]}$. It finds that futures price changes in a random walk process, and accepts the hypothesis that futures exchanges are weak-effective. Some authors mainly utilize Rescaled Range Analysis method to calculate the Hurst Exponent, and then the validity of stock index futures and commodity futures markets is verified ${ }^{[5-7]}$.
Most studies on the effectiveness of futures market are concerned about the stock index futures market or the general commodity futures market ${ }^{[3-7]}$. The research on the effectiveness of electricity market is mainly for the verification of effectiveness of electric energy market ${ }^{[8]}$. No scholars have studied the effectiveness of electricity futures market.

The rest of the paper is organized as fellows: Section 2 presents the definitions and model and methodology of the empirical analysis, Section 3 summarizes the results of empirical analysis and finally Section 4 presents the summary and conclusions of this work.

\section{Hurst Exponent and R/S analysis method}

Hurst exponential hydrology expert Harold Hurst proposed a parameter in the middle of the twentieth century to distinguish whether time series data follows random walk or biased random walk. And he also proposed a classical method for calculating this parameter: R/S analysis method.

\subsection{The calculation method of Hurst Exponent}

Quite a lot of empirical statistics show that in the financial market, the yield of some financial commodities is not a standard random walk motion unrelated to past returns. In order to eliminate the influence of factors such as the autocorrelation of futures prices, we first need to make a first-order difference to the closing price timing $\left\{p_{j}\right\}$ to calculate the sequence of futures price changes $\left\{x_{i}\right\}$ :

\footnotetext{
* Corresponding author: fordevoted@foxmail.com
} 


$$
x_{i}=\log \left(\frac{p_{j+1}}{p_{j}}\right)
$$

Where, $p_{j}$ is the closing price of futures market, $j=\mathrm{N}+1$, and $x_{i}$ is the variable value of futures price.

Divide the futures price sequence into quantitiy $A$ equal-length sub-intervals. For each sub-interval, let:

$$
X_{t, a}=\sum_{u=1}^{t}\left(x_{u, a}-M_{a}\right)
$$

Where, $X_{t, a}$ is the cumulative deviation of the $\mathrm{t}$-th element in the interval $a, x_{u, a}$ is the $u$-th element in the interval $a$ and $M_{a}$ is the average value of the n-th interval.

Let the range $R_{a}$ satisfy the following formula:

$$
R_{a}=\max \left(X_{t, a}\right)-\min \left(X_{t, a}\right)
$$

Where, $R_{a}$ is the range of the interval $a$.

Set $S_{a}$ as the sample standard deviation of interval $a$, then the rescaling range $R_{a} / S_{a}$ can be defined. The mean value of the mean relabeled range can be obtained by taking the mean value of the relabeled range of all intervals:

$$
(R / S)_{n}=\frac{1}{\mathrm{~A}} \times \sum_{a=1}^{\mathrm{A}} \frac{R_{a}}{S_{a}}
$$

Where, $n$ is the length of intervals。

According to Hurst's experience, the following relationships are satisfied for different segmentation situations:

$$
(R / S)_{n}=K \times n^{H}
$$

Where, $K$ is constant, $H$ is the corresponding Hurst Exponent.

\subsection{Hurst Exponent and aperiodic cycle}

The aperiodic cycle of time series can be observed by $\mathrm{R} / \mathrm{S}$ analysis, and the average cycle length can be estimated by two methods:

One is estimating by drawing the graph of $\log \left((\mathrm{R} / \mathrm{S})_{\mathrm{n}}\right) / \log (\mathrm{n})$. For the $\log / \log$ graph of $\mathrm{R} / \mathrm{S}$ analysis, the end of each cycle is the beginning of the next cycle. The average cycle length can be estimated by turning points in the graph.

The other one is V Statistical Method, which gives a more precise measure of cycle length. It can be expressed as

$$
V_{n}=\frac{(R / S)_{n}}{\sqrt{n}}
$$

If the process is independent and random $(\mathrm{H}=0.5)$, the V statistic drawn based on formula (5) for Log (n) should be flat. If the process is anti-persistent and $\mathrm{R} / \mathrm{S}$ changes at a scale slower than the time square root $(\mathrm{H}<$ 0.5 ), the graph should be tilted downward. If the process is continuous and $\mathrm{R} / \mathrm{S}$ changes in scale faster than the time square root $(\mathrm{H}>0.5)$, then the graph should be tilted upward. Through the V-statistics, breakpoints can be found and the maximum value of $F$ in each interval can be checked to estimate the cycle length of each frequency.

\subsection{Estimation and Test of Hurst Exponent}

Through logarithmic transformation of formula (5), the Hurst Exponent can be estimated by the least square method.

One of the easiest ways to test the effectiveness of Hurst Exponent is to randomly scramble the data. The frequency distribution of the actual observation remains unchanged. Use the scrambled data to calculate the Hurst index. If the sequence is truly independent and there is no long-term memory effect or correlation between observations, then the Hurst Exponent should remain unchanged. Disruption of data should have no effect on the qualitative nature of data. Conversely, if there is a long-term memory effect, the order of the observed data is important, and disrupting the data will destroy the structure of system. The Hurst Exponent calculated should be very different or close to 0.5 .

\subsection{Characteristics of Hurst Exponent}

Exponential $\mathrm{H}$ is a statistic between 0 and $1 . \mathrm{H}$ values in different intervals have different representative meanings. The specific characteristics are as follows:

A. When $\mathrm{H}=0.5$, the time series obeys the standard geometric Brownian motion, showing the characteristics of normal distribution. The variables are random and unrelated, and the present data has no influence on the future.

B. When $0<\mathrm{H}<0.5$, the time series show antipersistent state, and the closer the $\mathrm{H}$ value is to 0 , the more obvious the fractal characteristics are, the stronger the anti-persistent state is.

C. When $0.5<\mathrm{H}<1$, the time series has persistence and long memory. In this state, the increment of time series in the later period is the same as that in the previous period, that is, if the system goes up in the previous period, then in the later period, the system will still go up with great possibility. At this time, the time series has a trend. The closer $\mathrm{H}$ is to 1 , the stronger the trend of time series is. The closer $\mathrm{H}$ is to 0.5 , the weaker the trend of time series is and the closer it is to random walk.

D. When $\mathrm{H}=1$, it shows that this time series is completely predictable, and we can use the present data to predict the future.

The closer the Hurst Exponent approaches 0.5, the more efficient the market is. On the contrary, the closer the Hurst Exponent approaches 1 or 0 , the more ineffective the market is.

\section{The empirical analysis}

\subsection{Data Selection and Processing}

This paper selects the closing prices of PJM Western Day-ahead non-peak futures (PWON9), PJM Monthly 
Swap Options (DMYM9) and PJM Monthly Peak Futures (DMM9) from April 1, 2014 to June 12, 2019 (a total of 1310 data points) as samples, a total of three samples to meet the needs of large sample size and diversification. Because Hurst Exponent is a robust nonparametric statistical method, individual singular values do not change its properties significantly, and it focuses on whether there is a long-term trend in the measurement sequence. It is an asymptotic property of large samples. Because the futures varieties currently trading on the market are established in a relatively short period, segmentation will lead to too small samples. Therefore, the data are not segmented and filtered.

\subsection{Data Selection and Processing}

Hurst Exponent can not be calculated by fixed statistical software. This paper calculates Hurst Exponent by MATLAB programming. Restricted by the length of an article, this paper briefly describes the process of $\mathrm{R} / \mathrm{S}$ analysis by taking the non-peak period futures in the western part of PJM as an example.

As shown in Fig. 1, there is no obvious turning point by observing the trend of graph change. The $\mathrm{V}$ statistic oscillates and rises in the whole sample interval, and there is no average cycle. This finding is also confirmed in Fig. 2. There is no obvious turning point in Figure 2.

Through regression analysis of the corresponding linear equation of formula (6), $\mathrm{n}$ in the sample satisfies and the regression results are very good. The Hurst Exponent is 0.65498 , greater than 0.5 , which means that the sequence has a certain long-term memory. In order to test the validity of the results, Futures sequence data is randomly disrupted. And then the Hurst Exponent is estimated to be 0.50143 , which indicates that the longterm memory structure in the sequence is broken.

In addition, this paper shows the curve charts of PJM West Day-ahead non-peak futures (dark color) and Random remake futures sequence (light color), so that the analysis results can be seen intuitively, as shown in Figure 2.

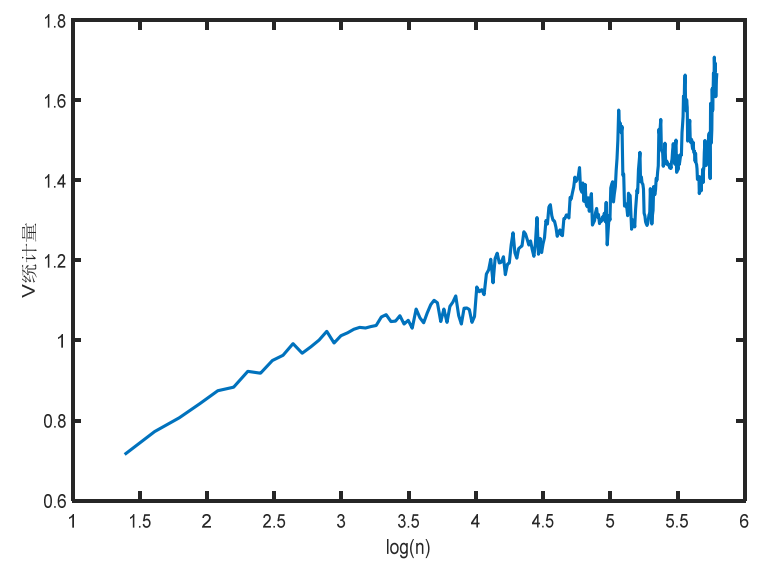

Fig. 1. V Statistics of PJM West Day-ahead non-peak futures.

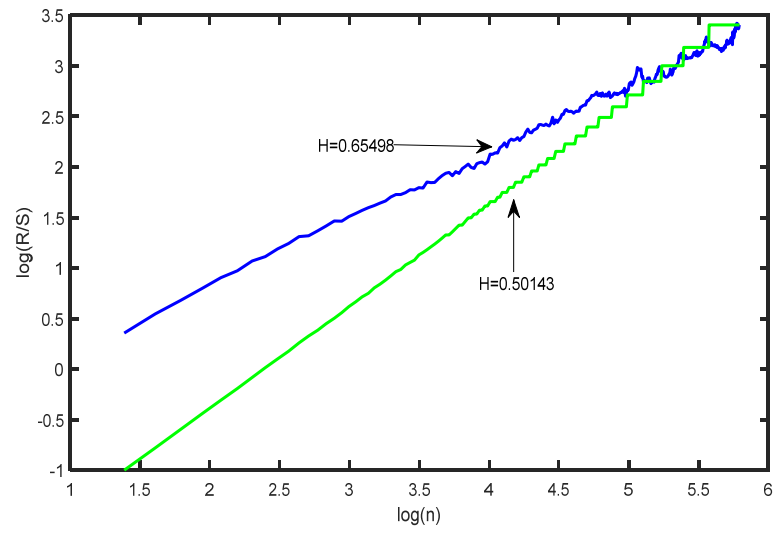

Fig. 2. $\log (n)$ and $\log ((R / S) n)$ diagrams of PJM West Dayahead non-peak futures.

In order to measure PJM financial market comprehensively, this paper also analyses the results of PJM monthly swap options (DMYM9) and PJM monthly peak futures (DMM9). The analysis results are shown in Table 1.

Table 1. R/S Analysis of prices of products in PJM Financial Market.

\begin{tabular}{|c|c|c|c|}
\hline Product type & $\begin{array}{c}\text { Hurst } \\
\text { value of } \\
\text { original } \\
\text { sequence }\end{array}$ & $\begin{array}{c}\text { Hurst value } \\
\text { after random } \\
\text { rearrangement }\end{array}$ & $\begin{array}{c}\text { Average } \\
\text { Period }\end{array}$ \\
\hline $\begin{array}{c}\text { PJM Western } \\
\text { Day-ahead } \\
\text { non-peak } \\
\text { futures } \\
\text { (PWON9) }\end{array}$ & 0.68086 & 0.47642 & 1315 \\
\hline $\begin{array}{c}\text { PJM monthly } \\
\text { swap options } \\
\text { (DMYM9) }\end{array}$ & 0.57398 & 0.52564 & 1315 \\
\hline $\begin{array}{c}\text { PJM monthly } \\
\text { peak futures } \\
\text { (DMM9) }\end{array}$ & 0.65498 & 0.50143 & 1315 \\
\hline
\end{tabular}

\section{Conclusion}

Through empirical analysis, we can draw the following conclusions:

The price fluctuation of PJM power financial products has a more obvious persistent state. The Hurst Exponent of the three types of financial products deviates from 0.5 to a certain extent, and is greater than 0.5. The PJM power financial market is subject to fractional Brownian motion or biased random walk process. The fluctuation is relatively smooth, and the variables are not independent, but positively correlated. Time series have the characteristics of persistence or trend enhancement, which means that if the sequence is up (down) at a certain moment, then it is likely to continue up (down) at the next moment.

PJM power financial market is more effective, and PJM power option market is more effective than power futures market. The three types of products are found to 
have obvious average cycle. In the Hurst Exponent of the three types of products, the PJM monthly swap option has the smallest value, the least deviation degree and the stronger the market efficiency.

Using the $\mathrm{R} / \mathrm{S}$ analysis method to calculate the Hurst exponent and evaluate the effectiveness of the power derivatives market, China can provide a certain reference for measuring whether the market is effective in designing the power financial market in the future.

\section{Acknowledgment}

This work is funded by the State Grid Science and Technology Project of China (Research on Design and Pricing Technology of Power Finance Products).

\section{References}

1. Eugene F. Fama. Efficient Capital Markets: A Review of Theory and Empirical Work, Journal of Finance, Vol. XXV, No. 2, 383-417 (May 1970)

2. .E.Peters, Fractal Market Analysis: Applying Chaos Theory to Investment and Economics, John Wiley \& Sons, Inc (1994)

3. Wang Zhiqiang, Xu Yafan, Zhu Lihong. Market Effectiveness Test of Dalian Commodity Exchange [J]. Research on Financial Issues, 1998 (12): 54-56 (1998)

4. Shang Rubin, Wu Xuan. Theoretical and Empirical Research on Futures Market Effectiveness [J]. Journal of Management Engineering , 14 (4): 83-85 (2000)

5. Zhao Peng. Research on Futures Price Return and Fluctuation in China's Futures Market [J]. Management Observation, 2008 (22): $57-59$ (2008)

6. Meng Xianglei. RESEARCH ON THE EFFICIENCY OF CHINA STOCK INDEX FUTURES MARKET BASED ON HURST EXPONENT [D]. Harbin University of Technology, (2014)

7. Zhou Liang. Study on Fractal Characteristics of China Commodity Futures Market [J]. Zhejiang Finance, 2017 (3): 53-60 (2017)

8. Cui He-rui, Yang Li. Effectiveness Analysis and Evaluation Model of China's Electricity Market [J]. Journal of Electricity, 26 (5): 399-405 (2016)

9. H.Hurst, Long term storage capacity of reservoirs, Trans. Am. Soc. Civ. Eng. 6 :770-799 (1951) 